\title{
Ácidos graxos poli-insaturados $n-3$ e n-6: metabolismo em mamíferos e resposta imune
}

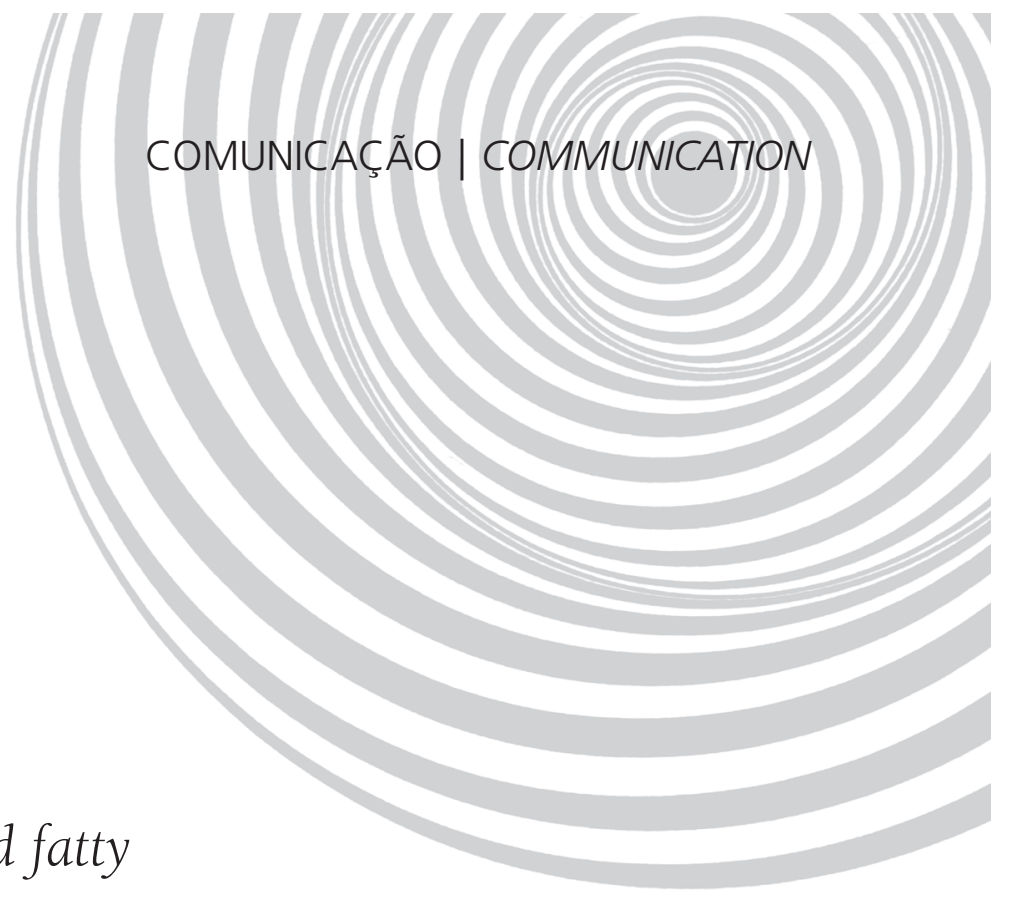

\author{
Omega-3 and omega-6 polyunsaturated fatty \\ acids: metabolism in mammals \\ and immune response
}

João Ângelo de Lima PERINI ${ }^{1}$

Flávia Braidotti STEVANATO ${ }^{1}$

Sheisa Cyléia SARGI²

Jeane Eliete Laguila VISENTAINER ${ }^{2}$

Márcia Machado de Oliveira DALALIO²

Makoto MATSHUSHITA ${ }^{1}$

Nilson Evelázio de SOUZA ${ }^{1}$

Jesuí Vergílio VISENTAINER ${ }^{1}$

RE S U M O

A experimentação animal apresenta uma grande importância para o desenvolvimento da ciência. O uso de camundongos em experimentos ocorre devido à semelhança destes animais com os seres humanos, fácil criação e manutenção e resposta experimental bastante rápida. Esses animais possuem as mesmas enzimas dessaturases e elongases que os humanos, por isso são usados em pesquisas envolvendo incorporação e síntese de ácidos graxos em tecidos. Os ácidos graxos da família ômega-3 e ômega-6 são de suma importância na dieta humana, pois estes não são sintetizados pela síntese de novo e são precursores dos ácidos graxos poli-insaturados de cadeia muito longa, como os ácidos eicosapentaenóico, docosahexaenóico e araquidônico. Estes desempenham funções importantes no organismo, como a síntese de eicosanóides que estão envolvidos diretamente no sistema imune e nas respostas inflamatórias. A razão entre o consumo de ácidos graxos n-6 e n-3 na dieta é um importante fator para determinar a ingestão adequada de ácidos graxos bem como prevenir o aparecimento de doenças. Este artigo tem como objetivo avaliar a incorporação de ácidos graxos em tecidos de animais e discutir a importância dos ácidos da família n-3 e seus metabólitos no sistema imunológico.

Termos de indexação: Ácidos graxos poli-insaturados. Ácidos graxos ômega-3. Camundongos. Eicosanóides.

\footnotetext{
1 Universidade Estadual de Maringá, Departamento de Química. Maringá, PR, Brasil.

2 Universidade Estadual de Maringá, Departamento de Análises Clínicas. Av. Colombo, 5790, 87020-900, Maringá, PR, Brasil.

Correspondência para/Correspondence to: J.V. VISENTAINER. E-mails: <jvvisentainer@uem.br>; <jesuiv@gmail.com>.
} 
1076 | J.A.L. PERINI et al.

\section{A B S T R A C T}

Experiments with animals are very important for the improvement of science. The use of mice in experiments is due to their similarity with humans, the easy of raising and maintaining them and their very fast response. These animals have the same desaturase and elongase enzymes as humans and so they are used in research involving the incorporation and synthesis of fatty acids in tissues. The fatty acids omega-3 and omega- 6 are extremely important in the human diet because they are not synthesized de novo and are precursors of very long-chain polyunsaturated fatty acids, such as the eicosapentaenoic, docosahexaenoic and arachidonic acids. These acids play important roles in animals, such as precursors of eicosanoids, which are directly involved in the immune system and inflammatory response. The dietary n-3:n-6 intake ratio is important for assessing proper fatty acid intake and for preventing the development of diseases. Thus, this article assessed the incorporation of fatty acids in animal tissues and discussed the importance of $n-3$ fatty acids and its metabolites for the immune system.

Indexing terms: Polyunsaturated fatty acids. Omega-3 fatty acids. Mice. Eicosanoids.

\section{N T R O D U Ç Ã O}

Os lipídeos desempenham uma variedade de funções celulares e são a principal forma de armazenamento de energia na maioria dos organismos. Atuam no transporte de vitaminas lipossolúveis, atuam como precursores de hormônios e determinados grupos são considerados funcionais ${ }^{1}$.

Componentes lipídicos, principalmente os Ácidos Graxos (AG), se encontram distribuídos em todos os tecidos, principalmente nas membranas celulares e células de gordura. Desempenham importante função na estrutura da membrana celular, nos processos metabólicos e na produção de eicosanóides².

Os ácidos graxos são classificados conforme a presença de duplas ligações (insaturações) entre as cadeias de carbono. São denominados Ácidos Graxos Saturados (AGS) na ausência de duplas ligações; Ácidos Graxos Monoinsaturados (AGMI) pela presença de uma insaturação; Ácidos Graxos Poli-Insaturados (AGPI) pela presença de duas ou mais insaturações ${ }^{1}$. Quanto ao tamanho da cadeia carbônica, os AGPI que possuem número de átomos de carbono $\geq$ a 16 são denominados Ácidos Graxos Poli-Insaturados de Cadeia Longa (AGPI-CL). Os AGPI com número de átomos de carbono $\geq$ a 20 são denominados Ácidos Graxos Poli-Insaturados de Cadeia Muito Longa (AGPI$-(\mathrm{ML})^{3}$.
Dentre os AGPI, os ácidos graxos poli-insaturados ômega-3 (AGPI n-3) e ácidos graxos poli-insaturados ômega-6 (AGPI n-6) se destacam por apresentarem efeitos benéficos à saúde humana. A manipulação destes AG na dieta fornece dados para se verificar a incorporação e síntese dos mesmos nos tecidos. Em experimentos com animais, os camundongos (Mus musculus) vêm sendo bastante empregados nestes estudos, devido a sua semelhança com humanos e por fornecerem informações do organismo como um todo.

Os AGPI n-3 e n-6 possuem vários efeitos sobre a resposta imune e inflamatória. O balanço na ingestão destes ácidos graxos, e consequentemente a incorporação dos AGPI na membrana das células imunes, é importante para determinar a severidade do processo inflamatório. Os AGPI n-3 possuem efeitos supressores, como inibição da proliferação de linfócitos, produção de anticorpos e citocinas, expressão de moléculas de adesão e ativação das células Natural Killers (NK). No entanto, os AGPI n-6 possuem ambos os efeitos, tanto inibitório quanto estimulatório da resposta imune $e^{4,5}$.

Os objetivos desse estudo foram avaliar a incorporação dos ácidos graxos em tecidos de animais e destacar a importância dos ácidos da família n-3 e seus metabólitos no sistema imunológico. 


\section{Animais experimentais e o homem}

O emprego de animais experimentais nas pesquisas científicas vem sendo feito desde antes de 1900, quando as espécies mais usadas para os experimentos eram galinhas, coelho e cachorro, utilizados no tratamento da raiva e deficiência de vitamina $B^{6}$.

A experimentação animal apresenta uma grande importância para o desenvolvimento da ciência e tecnologia, na descoberta de tratamentos para diferentes enfermidades, descoberta de medidas profiláticas, principalmente devido ao fato dos modelos animais fornecerem informações sobre o organismo em geral ${ }^{7}$.

Os trabalhos com humanos tornam-se difíceis por apresentarem uma enorme variabilidade genética e grande dificuldade no controle da dieta alimentar ${ }^{7}$. Além disto, os trabalhos são limitados e envolvem parâmetros éticos, exigem requisitos para resguardar a integridade física e emocional dos investigados 8 .

Amostras com número suficiente de investigados no intuito de obter uma representatividade estatística e acompanhá-la por todo o período da investigação, normalmente é tarefa trabalhosa, e demanda longo tempo. Outro fator importante é a coleta do material patológico que pode exigir procedimentos invasivos, dolorosos e demorados. Estas são algumas das limitações que podem dificultar ou inviabilizar uma investigação em seres humanos. O uso de modelos animais pode superar estas limitações e proporcionar uma investigação mais rápida e menos onerosa ${ }^{8}$.

Os projetos de pesquisa que utilizam modelos animais devem ser analisados por Comitês de Ética em Pesquisa, visando à qualificação dos projetos e evitando o uso inapropriado ou abusivo de animais em experimentação. Em 1991 o Colégio Brasileiro de Experimentação Animal, cria os Princípios Éticos na Experimentação Animal, postulando 12 Artigos que passam a nortear a conduta dos professores e dos pesquisadores na prática do uso de animais?.
Dentre todos os animais experimentais, os camundongos são os mais utilizados e os mais conhecidos cientificamente em razão de sua semelhança com humanos ${ }^{10}$. São mamíferos, monogástricos, grande similaridade biológica e disposição anatômica das estruturas internas, similaridade genética ${ }^{11}$, vias metabólicas semelhantes aos do homem e a homologia do DNA codificador entre estas duas espécies está entre 70\% e 90\%. Os camundongos são membros da classe Mammalia, ordem Rodentia, família Muridae, gênero Mus, espécie Mus musculus e foram reconhecidos como animais de laboratório no século XIX, tornando-se um importante modelo experimental para estudos genéticos ${ }^{6}$. O camundongo como animal de laboratório se deve ao fato de serem animais pequenos, fácil criação, manutenção e manuseio, bastante prolífero, resistência a infecções e traumas cirúrgicos e larga diversidade genética' ${ }^{12}$.

O camundongo é uma espécie que se adapta a uma grande variedade de condições ambientais. Vive em biotérios, os quais dependem do homem para todas suas necessidades e bem-estar. Fatores como temperatura, luz, umidade devem ser controlados. Sua alimentação em geral é apresentada na forma de "pellets", diminuindo o desperdício e tornando o alimento mais fácil de ser manuseado e oferecido em comedouros situado na tampa das gaiolas ${ }^{13}$.

Devido à necessidade de avaliar o comportamento de algumas dietas no metabolismo destes animais, pela análise de sangue ou dos tecidos, a eutanásia é necessária. Eutanásia significa morte sem dor ou sofrimento. Deve ser de fácil aplicação, rápida, baixo custo, e não permitir espalhamento de sangue pelo local evitando-se contaminação ${ }^{14}$. Os métodos mais aceitáveis para este procedimento em camundongos são os métodos químicos que utilizam anestésicos por inalação e barbitúricos. Os métodos físicos compreendem deslocamento cervical, traumatismo craniano, decapitação, exanguinação, tiro por arma de fogo e eletrocussão. Vale salientar que o método físico só deve ser empregado quando outros métodos invalidam uma determinada informação ou pesquisa ${ }^{15}$. 
1078 | J.A.L. PERINI et al.

\section{Metabolismo dos ácidos graxos poli-insaturados e importância na saúde humana}

Os ácidos graxos poli-insaturados apresentam as insaturações separadas por um carbono metilênico $\left(\mathrm{CH}_{2}\right)$. Dentre estes ácidos destacamse aqueles pertencentes à família ômega- 6 , como os ácidos linoléico (18:2n-6, LA) e o araquidônico (20:4n-6, AA) e à família ômega-3 como os ácidos alfa-linolênico (18:3n-3, LNA), eicosapentaenóico (20:5n-3, EPA) e docosahexaenóico (22:6n-3, DHA). A Figura 1 ilustra a existência da primeira insaturação no sexto carbono, enumerado a partir do grupo metil terminal, para um ômega- 6 e no terceiro carbono para um ômega-3.

Os ácidos LA e LNA são precursores dos AGPI-CML pertencentes às famílias ômega- 6 e ômega-3, respectivamente, através dos processos de elongação (enzimas elongases) e dessaturação (enzimas dessaturases) da cadeia carbônica, conforme Figura 2. O processo ocorre no retículo endoplasmático, especialmente no fígado.
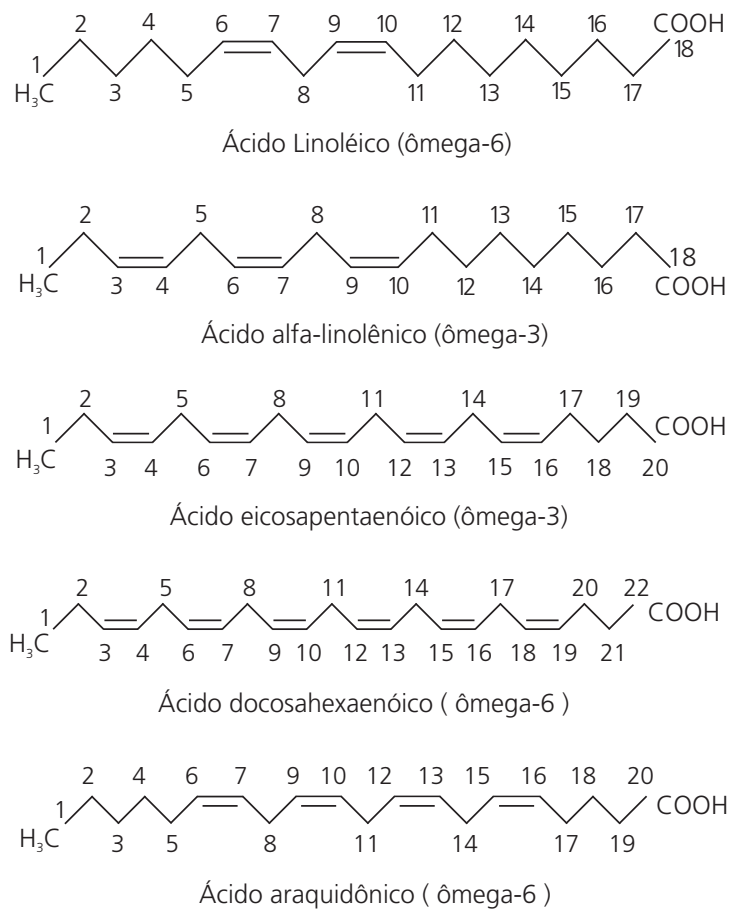

Figura 1. Estruturas dos ácidos ômega-6 e 3.
As dessaturases atuam oxidando dois carbonos da cadeia com formação de duplas ligações e as elongases atuam adicionando dois átomos de carbono à cadeia. Nos mamíferos, as dessaturases são capazes de introduzir duplas ligações nas posições $\Delta^{5}, \Delta^{6}$ e $\Delta^{9}$, sendo que as enzimas $\Delta^{5}$ e $\Delta^{6}$ atuam na dessaturação dos AGPI, enquanto a $\Delta^{9}$ dessaturase atua na síntese dos ácidos graxos monoinsaturados ${ }^{16,17}$. Os AG n-3 e AG n-6 competem pelas mesmas enzimas envolvidas nas reações de dessaturação e elongação, sendo que essas enzimas têm maior afinidade pelos AG n-318.

Nos mamíferos, os ácidos de até 16 átomos de carbono (ácido palmítico, 16:0) são sintetizados pela enzima ácido graxo sintase (EAGS), pela síntese de novo, em quatro etapas. Inicia com a elongação de um grupo primário (acetil ou propionil) com duas unidades de carbono doados a partir do malonil-CoA e o NADPH é utilizado como agente redutor na reação de elongamento. Essa reação é repetida sete vezes em forma cíclica, para que a EAGS sintetize o ácido palmítico $(16: 0)^{19}$.

O processo de elongação começa com a condensação de uma molécula de acetil-CoA e malonil-CoA, resultando em uma molécula de $\beta$-cetoacil-CoA. O segundo passo é redução que utiliza NADPH, onde $\beta$-cetoacil-CoA é convertido em $\beta$-hidroxiacil-CoA. Este é desidratado na terceira etapa resultando na molécula de enoil-CoA, que precisa ser reduzida pela enzima enoil-redutase na quarta etapa, para que o ciclo de elongamento esteja completo e gere um aumento de um grupo acil na cadeia ${ }^{19}$.

A Figura 3 mostra uma representação resumida do metabolismo de ácidos graxos em camundongos.

\section{Essencialidade dos ácidos graxos}

São Ácidos Graxos Essenciais (AGE), para os mamíferos, aqueles que não podem ser sintetizados pelo organismo e devem ser fornecidos 


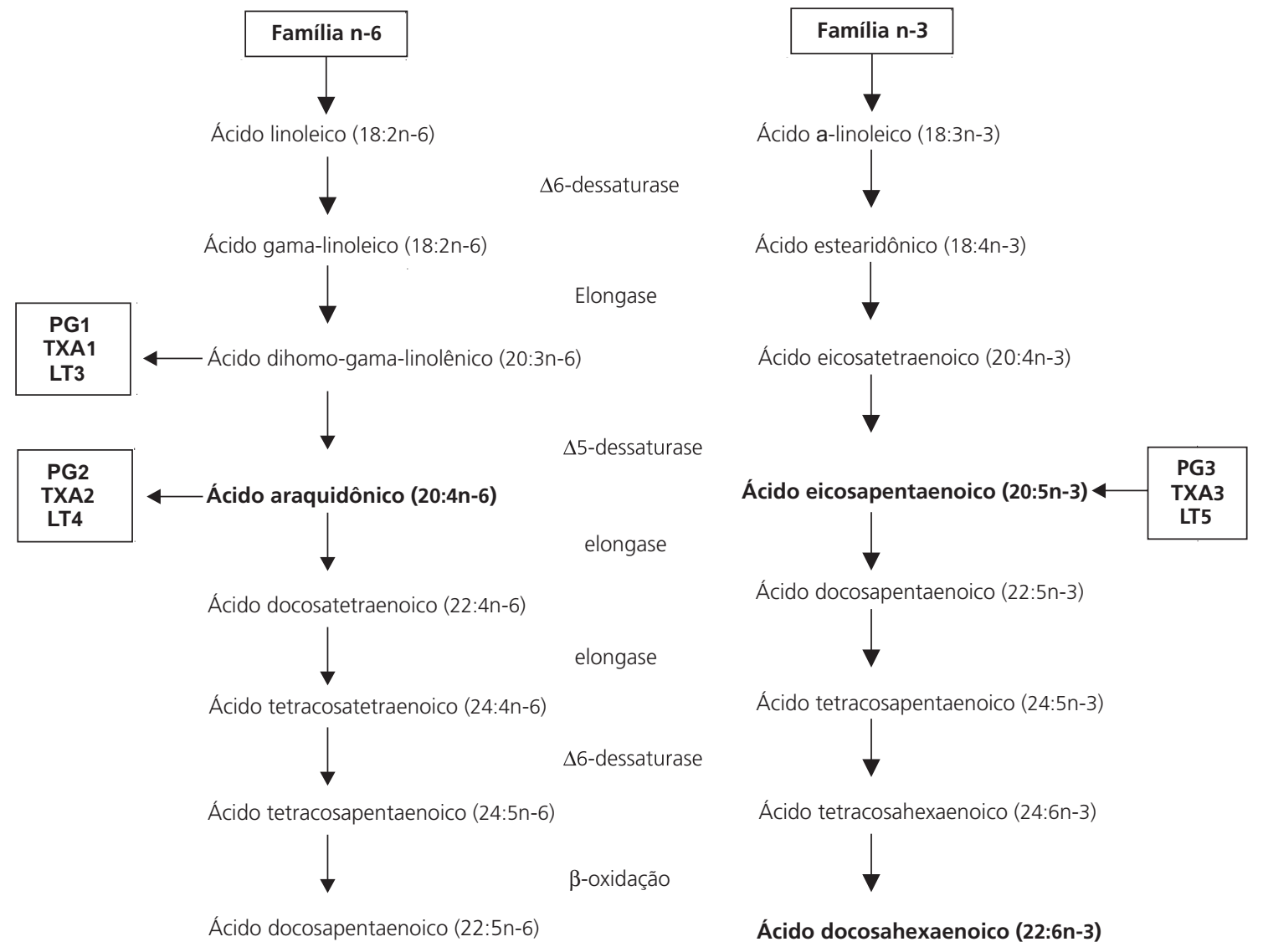

Figura 2. Metabolismo dos ácidos graxos das famílias n-6 e n-3.

Nota:PG1: prostaglandinas série 1; PG2: prostaglandinas série 2; PG3: prostaglandinas série 3; TXA1: tromboxanos série 1; TXA2: tromboxanos série 2; TXA3: tromboxanos série 3; LT3: leucotrienos série 3; LT4: leucotrienos série 4; LT5: leucotrienos série 5.

através da dieta. No entanto, deve-se restringir cada vez mais o número de ácidos graxos essenciais que possam realmente ser considerados estritamente essenciais. Não basta saber se um determinado ácido graxo tem a capacidade de curar manifestações patológicas ou prevenir doenças, é necessário estabelecer se um ácido graxo não é sintetizado pelas células do animal em estudo a partir de um ácido graxo precursor ${ }^{20}$.

Neste trabalho, com o propósito de consignar uma atribuição que deixassem claras as denominações ácidos graxos estritamente essenciais e essenciais, estabeleceu-se que os ácidos graxos linoléico (18:2n-6, LA) e alfa-linolênico (18:3n-3, LNA) são denominados de estritamente essenciais, pois não são sintetizados pelo homem e devem ser obtidos através da dieta. Os ácidos graxos que são sintetizados (derivados) a partir dos precursores ácidos linoléico e alfa-linolênico, conforme Figura 2, são denominados ácidos graxos essenciais.

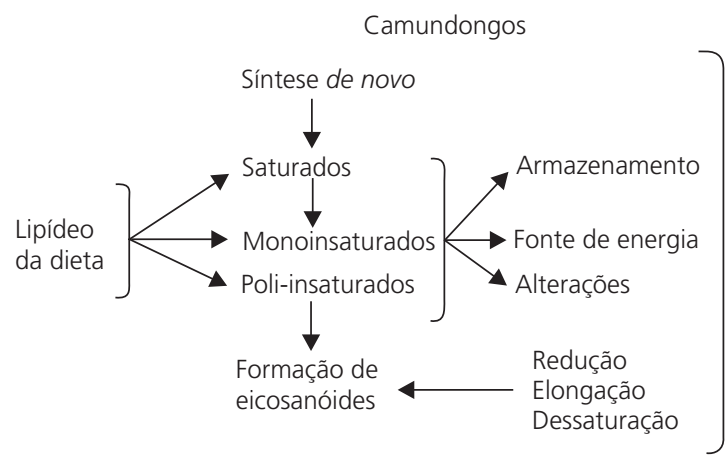

Figura 3. Representação do metabolismo lipídico em camundongos. 
Nesse trabalho, faz-se o seguinte esclarecimento. Segundo Ewin ${ }^{21}$, à medida que envelhecemos, o organismo pode perder a capacidade de transformar um ácido graxo (precursor) em seus derivados (Figura 2). Por exemplo, a idade pode afetar a atividade da enzima $\Delta 6$-dessaturase, responsável pela formação de ácidos graxos tanto da família n-3 como n-6. A baixa atividade ou insuficiência dessa enzima causa deficiência dos ácidos graxos sequenciais. No caso da perda total da atividade da enzima, os ácidos gama-linolênico (18:3n-6) e o estearidônico (18:4n-3), serão considerados estritamente essenciais, uma vez que eles não serão sintetizados pelo organismo e devem ser obtidos da dieta. Assim, na perda de atividade das enzimas subsequentes (elongases e dessaturases), esta analogia deve ser considerada para todos os ácidos graxos das famílias. Desta forma, um ácido graxo poderia ser considerado estritamente essencial nas etapas da vida em que não pudesse ser sintetizado a partir do precursor fornecido na dieta. Este mesmo ácido não seria essencial naqueles indivíduos capazes de sintetizá-lo através de um precursor.

Nos últimos anos, as investigações científicas têm comprovado que as dietas com quantidades adequadas de AGPI n-3 e AGPI n-6 desempenham papel importante na prevenção de doenças cardiovasculares e aterosclerose ${ }^{22,23}$, doenças inflamatórias crônicas ${ }^{24}$, inibição da vasoconstrição e agregação plaquetária ${ }^{25}$, no crescimento fetal e desenvolvimento neural ${ }^{26}$, ação anti-inflamatória e antitrombótica ${ }^{27}$, ação sobre a prevenção do câncer ${ }^{28}$, e participação nas funções imunomoduladoras ${ }^{29}$. Baixas concentrações ou ausência desses componentes aceleram o processo de envelhecimento e aumentam a probabilidade de desenvolvimento de várias doenças dege-nerativas e cardiovasculares ${ }^{30}$.

O Ácido Docosahexaenóico (DHA) tem importante função no funcionamento e desenvolvimento da retina ${ }^{30}$ e cérebro ${ }^{31}$, sendo predominante na maioria das membranas celulares. Estudos realizados com animais observaram que a deficiência de AGPI n-3 diminui a concentração de DHA nos tecidos do cérebro e retina, influenciando nas funções destes ${ }^{32}$.

O Ácido Eicosapentaenóico (EPA) e o Ácido Araquidônico (AA) dão origem aos eicosanóides, mediadores inflamatórios de origem lipídica, sendo o AA o principal substrato para síntese dos eicosanóides ${ }^{33,34}$.

Pesquisas indicam que o EPA interfere na produção de Prostaglandina (PG) da série 3, substância que se assemelha aos hormônios e que regula e protege o organismo de efeitos, como agregação plaquetária (devido à sua ação antitrombótica), inflamação e diminuição das respostas imunes ${ }^{35}$.

O AA é importante no crescimento fetal ${ }^{36}$, no controle da pressão sanguínea, desenvolvimento do cérebro e retina e no controle da agregação plaquetária ${ }^{30}$.

\section{Incorporação dos ácidos graxos poli-insaturados em mamíferos}

A incorporação e conversão dos AGPI n-3 e AGPI n-6 em AGPI-CML nos tecidos de mamíferos tem sido bastante descrita em fígado de ratos, onde as reações de dessaturação e elongação são importantes, em termos do fornecimento de metabólitos de LNA para outros tecidos $^{37}$. Esta conversão é possível em modelos animais, como em camundongos, pois estes possuem as enzimas dessaturases e elongases para que ocorra a síntese destes ácidos graxos ${ }^{38}$.

A conversão dos AG n-3 em seus derivados de cadeia longa (EPA e DHA) e sua subsequente incorporação nos tecidos de mamíferos é fortemente influenciada pelos níveis de LNA na dieta ${ }^{39}$.

Estudos realizados com humanos ${ }^{40}$, ratos $^{41}$ e hamsters ${ }^{42}$ demonstraram efetiva conversão do LNA em EPA e DHA. Estudos com ratos mostraram que a inclusão de óleo de linhaça na dieta aumentou o teor de LNA e EPA e em menor proporção de DHA no plasma e no fígado ${ }^{41}$. Há controvérsias em relação ao acúmulo de DHA a partir do LNA 
da dieta. Ratos alimentados com dieta enriquecida com LNA tiveram um acúmulo significativo de DHA no cérebro quando comparados com controles ${ }^{43}$. Porém, outros estudos com dietas similares não demonstraram acúmulo de DHA em diferentes tecidos de ratos ${ }^{44}$.

Além disto, a razão entre a ingestão de AG n-6 e AG n-3 é importante já que são metabolicamente e fisiologicamente diferentes e apresentam funções fisiológicas opostas. Um grande excesso de ácidos graxos de uma série na dieta pode inibir a dessaturação de quantidades menores de um ácido graxo de outra série ${ }^{45}$.

O excesso do ácido linoléico poderá impedir por efeito de competição pela enzima $\Delta 6$ dessaturase, a transformação do ácido alfa-linolênico em seus derivados de cadeia longa (EPA e DHA). Isto causa o desbalanceamento dos AG no organismo e a incorporação dos AGPI-CML nos tecidos, afetando o efeito destes ácidos graxos em doenças crônicas ${ }^{46}$. As dietas ocidentais são exemplos deste desequilíbrio dos ácidos graxos, pois são ricas em ácidos graxos n- 6 e baixas em ácidos graxos n-3, o que pode alterar a síntese dos eicosanóides.

Os eicosanóides são metabólitos oxigenados dos ácidos graxos essenciais compostos por Prostaglandinas (PG), Leucotrienos (LT), Prostaciclinas (PCI), Tromboxanos (TXs) e derivados dos ácidos graxos hidroxilados.

Um alto teor de AG n-6 na dieta favorece a formação elevada de eicosanóides a partir do $A A$, mais do que os eicosanóides formados a partir do EPA ${ }^{47}$. Os eicosanóides provenientes do AA são biologicamente ativos em pequenas quantidades e, se formados em elevadas quantidades, favorecem a síntese de eicosanóides inflamatórios e contribuem para formação de trombos e ateromas. Aumentar a ingestão de EPA e, consequentemente, diminuir a ingestão de $A A$, resulta na produção de compostos menos inflamatórios ${ }^{48}$.

Quando humanos ingerem AG n-3, os ácidos graxos EPA e DHA provenientes da dieta substituem parcialmente os AG n-6, principal- mente, o AA nas membranas e células do fígado, modificando a composição dos AGPI nos tecidos lipídicos em relação aos eicosanóides. Portanto, o metabolismo dos eicosanóides provenientes do AA é alterado, favorecendo a formação de eicosanóides anti-inflamatórios ${ }^{48}$.

Atualmente, a busca de fontes alternativas e complementares de ácidos graxos poli-insaturados ômega-3 tornou-se uma necessidade, a fim de se alterar a razão entre o somatório dos ácidos ômega-6/ômega-3 (n-6/n-3) ingeridos.

As quantidades de ácidos graxos e as razões entre os ácidos graxos das famílias $n-6$ e $\mathrm{n}-3$, ingeridas atualmente pelo homem, são difíceis de serem analisadas, pois dependem da fisiologia, disponibilidade de alimento e dieta de cada indivíduo. Ainda não foram precisamente estabelecidas as taxas mínimas do consumo de AG das séries n-3 e n- 6 para atender às exigências humanas destes nutrientes, porém, há necessidade de um equilíbrio entre as disponibilidades destes ácidos graxos na alimentação. De acordo com o Institute of Medicine ${ }^{49}$ a relação satisfatória da razão entre n-6/n-3 é de 10:1 a 5:1 e de acordo com base em experimentação animal esta razão é de $1: 1^{50}$ enquanto hoje, em dietas ocidentais, a relação atinge 10 a 25:1, causando um desbalanceamento dos ácidos graxos no organismo humano. No Brasil, informações sobre a razão n-6/n-3 na dieta dos brasileiros são restritas e, os resultados de pesquisas existentes incluem a composição em ácidos graxos de alguns alimentos isolados.

O ácido LA pode ser encontrado em abundância nos óleos de milho, girassol, soja, dentre outros. O ácido LNA é encontrado em plantas, animais e espécies marinhas ${ }^{51}$ e em concentrações elevadas na semente de linhaça (Linum usitatissimum), onde a quantidade de LNA varia de 44,6 a 51,5 do total de ácidos graxos. A linhaça, além de ser rica em AG n-3, também é rica em lignanas. Estes compostos estão associados ao efeito protetor e à inibição da metástase em tecidos de camundongos ${ }^{52}$ e atuam na prevenção de tumor mamário em camundongos ${ }^{53}$. 
1082 | J.A.L. PERINI et al.

\section{Papel dos ácidos graxos poli-insaturados no sistema imune}

O sistema imunológico está envolvido na defesa do organismo frente a agentes infecciosos como bactérias, vírus, fungos e parasitas; células tumorais e agressões externas ${ }^{54,55}$.

Este sistema é dividido em sistema imune inato e adquirido. O sistema imune inato é a primeira linha de defesa contra o microorganismo. Consiste em barreiras físicas e químicas (pele e mucosas); fatores solúveis (sistema complemento) e células fagocíticas (granulócitos, monócitos e macrófagos). Os linfócitos T citotóxicos naturais (linfócitos Natural Killer - NK) também têm um papel importante na resposta imune inata. As células fagocíticas expressam receptores de superfície específicos para os antígenos. A fagocitose é o primeiro estágio de eliminação de vários patógenos. Subsequente a destruição intracelular destes patógenos há a geração de peptídeos que junto com o complexo de histocompatibilidade principal (CPH) e células T iniciarão a resposta imune adquirida, que envolve a presença dos linfócitos. Este tipo de resposta é altamente específica, pois há memória imunológica, a qual é a base para uma resposta mais efetiva contra a re-exposição a um mesmo patógeno ${ }^{55}$.

A imunidade do tipo adquirida ou adaptativa quando envolve anticorpos é chamada de reposta humoral e é caracterizada pela produção de imunoglobulinas (Ig) específicas para antígenos específicos, a partir dos linfócitos B. Quando ocorre a infecção de uma célula por um patógeno intracelular, a resposta imune envolvida neste caso é a do tipo celular, mediada pelos linfócitos T. Os linfócitos T-Helper (CD4) podem ser subclassificados de acordo com os padrões de citocinas produzidas. O linfócito T-helper 1 (Th1) produz citocinas do tipo pró-inflamatórias, como interleucina (IL) 2, interferon gama (IFN $\gamma$ ) e o fator de necrose tumoral alfa (TNF- $\alpha$ ), os quais ativam macrófagos, células NK e linfócitos T citotóxicos (CD8). Já o linfócito T-helper 2 (Th2) secreta citocinas anti-inflamatórias, como a IL-5, fator de cres- cimento e transformação beta (TGF $\beta$ ), anticorpos específicos não protetores e IL-4, esta última estimula a produção de $\operatorname{lgE}$. E, recentemente, vem-se estudando as células T regulatórias (Treg) que produzem IL-10 e as células Th17 que produzem IL-1755,56.

Nos últimos anos, vários estudos têm se intensificado a fim de elucidar as funções dos eicosanóides na modulação das respostas inflamatórias e imunitárias ${ }^{57}$. Eles estão envolvidos na modulação da intensidade e duração da resposta inflamatória e também na regulação das funções dos linfócitos B e T55,5.

Além disso, os eicosanóides também estão envolvidos na função reprodutiva, formação de plaquetas e regulação da pressão arterial, secreção de ácidos gástricos, e uma variedade de outros processos importantes na saúde humana ${ }^{58}$.

A metabolização desses ácidos graxos ocorre por duas vias, a da ciclo-oxigenase (COX) que dá origem às $\mathrm{PG}, \mathrm{TX}$ e $\mathrm{PCl}$ e a via da Lipo-oxigenase (LOX) que sintetiza os LTs ${ }^{29}$.

A PGE2 e o LTB4 que pertencem à série par e são sintetizados a partir do AA constituem potentes mediadores pró-inflamatórios, sendo a PGE2 a mais importante. Ela induz a febre, promove a vasodilatação aumentando a permeabilidade vascular, potencializa a dor e o edema. Além de possuir um efeito imunossupressor, devido à inibição da proliferação de linfócitos e células natural killer (NK) e da produção de IL-2 e IFN- $\gamma$. Por outro lado, a PGE2 também possui características anti-inflamatórias quando inibe a produção de TNF- $\alpha$ e IL-134.

Estudos recentes têm demonstrado que a PGE2 induz a COX-2 nas células de fibroblastos, induz a produção de IL-6 por macrófagos, inibe a LOX-5, diminui a produção dos LTs da série 4 e promove a formação das lipoxinas. Desta forma, a PGE2 possui efeito pró-inflamatório e anti-inflamatório ${ }^{33}$

O aumento da incorporação do EPA nos fosfolipídios de membrana nas células imunes resulta no aumento da produção dos eicosanóides 
da série ímpar, como a PGE3 e LT5, que possuem características anti-inflamatórias, uma vez que o AA e o EPA competem pelo mesmo receptor na via da $\mathrm{COX}^{33,34}$. O EPA é o substrato preferencial da LOX, o que explica a maior formação dos derivados do EPA, quando comparado com o AA. Embora estes derivados possuam efeitos menos potentes do que os derivados do $A A^{58,59}$.

Um estudo que comparou os efeitos da PGE2 e PGE3 na produção de citocinas demonstrou que a PGE3 foi menos potente na indução do gene de expressão da COX-2 nos fibroblastos. Contudo, tanto a PGE2 quanto a PGE3 tiveram o mesmo efeito sobre a produção de TNF- $\alpha$ e IL-1 $\beta$ pelas células mononucleares estimuladas por endotoxinas ${ }^{58}$.

O AGPI n-3 parece inibir a atividade do fator nuclear $\chi \mathrm{B}(\mathrm{NF}-\chi \mathrm{B})$, o qual é responsável por induzir a expressão de vários genes de moléculas pró-inflamatórias, como moléculas de adesão, citocinas, quimiocinas e outros fatores de resposta imune ${ }^{59}$.

Modelos experimentais mostram que animais alimentados com dietas ricas em ácidos graxos n-3 tendem a diminuir a resposta proliferativa de linfócitos, apresentam diminuição das células NK e prejuízo na fagocitose ${ }^{60}$.

O óleo de peixe tende a diminuir a produção de PGE2. Já, na ação do LTB4, aumentaria a permeabilidade vascular, atuando como potente agente quimiotático para leucócitos, induzindo a liberação de enzimas lisossomais. Também atuaria inibindo a proliferação de Ly e promovendo a atividade natural de células NK. LTB4 aumenta a produção de TNF- $\alpha$, IL-1, IL-6, IL-12 e IFN- $\gamma$. Então, a liberação do AA desencadearia a síntese de mediadores opostos, onde o efeito fisiológico final seria governado pela concentração de tais mediadores ${ }^{29}$.

Geralmente, considera-se que o efeito anti-inflamatório do óleo de peixe se sobressaia em relação ao seu efeito supressor. Todavia, não há estudos com humanos para determinar a influência dose-dependente de óleo de peixe nos diversos parâmetros imunes ${ }^{55}$. A falta de dados sobre o efeito da dose-dependente pode ser devida aos resultados dos estudos serem com humanos saudáveis. Uma vez que a presença de uma condição inflamatória pode aumentar a sensibilidade dos efeitos imunomoduladores do EPA e DHA ${ }^{61}$.

De acordo com Kelley62, a adição do óleo de linhaça ( $15 \mathrm{~g}$ de LNA) a uma dieta hipolipídica (29\% das calorias diárias) de humanos resultou no declínio da proliferação dos linfócitos e atraso na resposta ao teste de hipersensibilidade cutânea após seis semanas, embora os níveis de anticorpos circulantes não tenham sido afetados.

Vale ressaltar que os ácidos graxos saturados e trans presentes nos alimentos industrializados influenciam no processo inflamatório, levando ao aparecimento das doenças crônicas não-transmissíveis, como as doenças cardiovasculares, diabetes e o câncer ${ }^{5,63}$. Portanto, a suplementação com AGPI n-3 aumenta a incorporação deste ácido graxo na membrana das células imunes, aumentando a produção dos mediadores lipídicos anti-inflamatórios, regulando a resposta à inflamação ${ }^{61}$.

Dependendo do ácido graxo precursor, haverá a formação de mediadores com características antagônicas e com diferentes atividades biológicas ${ }^{29}$. Ademais, pesquisas envolvendo os possíveis benefícios dos AGPI em toda a dinâmica imune e inflamatória ainda necessitam ser conduzidas.

\section{CONSIDERAÇÕES FINAIS}

O homem e os modelos experimentais, como os camundongos, apresentam algumas semelhanças entre si. São mamíferos monogástricos e possuem a mesma rota de síntese dos ácidos graxos poli-insaturados, usando as enzimas elongases e dessaturases. Devido a essa semeIhança, estes animais experimentais fornecem informações do organismo humano como um todo e são utilizados em diversos experimentos.

Dentre os ácidos graxos poli-insaturados, destacam-se os da família n-3 e n-6, pois estes 
não podem ser sintetizados pelo homem. O principal ácido da família n-3 é o ácido alfa-linolênico, a partir deste no organismo são sintetizados os precursores de cadeia muito longa, como ácido eicosapentaenóico e docosahexaenóico, pela rota sintética envolvendo as enzimas descritas acima. O mesmo acontece com os ácidos da família n-6, com o ácido linoléico, dando origem aos ácidos dihomo-gama-linolênico e araquidônico.

Os eicosanóides são moléculas derivadas dos ácidos graxos com vinte átomos de carbono. Estas substâncias exercem funções em diversos sistemas no organismo, estando diretamente ligados ao sistema imune e à resposta inflamatória, sendo que os eicosanóides derivados da família n-3 têm características anti-inflamatórias e os derivados da família n-6 têm características inflamatórias, quando em excesso no organismo.

\section{COLABORADORES}

J.A.L. PERINI realizou a coleta de dados sobre ácidos graxos poli-insaturados. F.B. STEVANATO realizou a coleta de dados sobre ácidos graxos ômega-3 e 6. S.C. SARGI realizou a coleta de dados sobre metabolismo dos camundongos. J.E.L. VISENTAINER realizou a coleta de dados sobre aspectos imunológicos. M.M.O. DALALIO coordenação de dados sobre aspectos imunológicos e metabolismo dos camundongos. M. MATSHUSHITA realizou a coleta de dados sobre ácidos graxos. N.E. SOUZA coordenação sobre ácidos graxos e referências bibliográficas. J.V. VISENTAINER coordenação geral do trabalho e autor correspondente.

\section{REFERÊ NCIAS}

1. Youdim KA, Martin A, Joseph JA. Essential fatty acids and the brain: possible health implications. Int J Dev Neurosci. 2000; 18(4/5):383-99.

2. Wanten GJ, Calder PC. Immune modulation by parenteral lipid emulsions. Am J Clin Nutr. 2007; 85(5):1171-84.

3. Martins CA, Almeida, WV Ruiz MR, Visentainer JEL, Matshushita M, Souza, NE, et al. Ácidos graxos poliinsaturados ômega-3 e ômega-6: importância e ocorrência em alimentos. Rev Nutr. 2006; 19(6): 761-70. doi: 10.1590/S1415-52732006000600 011.
4. Andrade PMM, Carmo MGT. Ácidos graxos n-3: um link entre eicosanóides, inflamação e imunidade. Rev Mn-Metabólica. 2006, 8(3):135-43.

5. Calder PC, Albers R, Antoine JM, Blum S, BourdetSicard R, Ferns GA, et al. Inflammatory Disease Processes and Interactions with Nutrition. Br J Nutr. 2009; 101(S1):S1-S45.

6. Cardoso TAO. Biossegurança no manejo de animais em experimentação. In: Oda LM, Ávila S. Biossegurança em laboratórios de saúde pública. Brasília: Fiocruz; 1998.

7. Snitkoff GG. Testes biológicos. In: Gennaro AR. A ciência e a prática da farmácia. Rio de Janeiro; 2004.

8. Shnaider TB. Ethics and research. Acta Cir Bras. 2008; 23(1):107-11.

9. Paixão RL. Os Desafios das Comissões de Ética no Uso de Animais. Ciênc Vet Tróp. 2008; 11(1):84-7.

10. Harris W.S. N-3 fatty acids and serum lipoproteins: animal studies. Am J Clin Nutr. 1997; 65 (suppl): $1611 S-16 S$.

11. Leon LR. The use of gene knockout mice in thermoregulation studies. J Therm Biol. 2005; 30(4):273-88.

12. Santos BF. Criação Criação e manejo de camundongos. In: Andrade A, Pinto S C, Oliveira RS. Animais de laboratório: criação e experimentação. Rio de Janeiro: Fiocruz; 2002.

13. Andrade MCR. A utilização de Símios do gênero Callithrix como modelo experimental. Bol informat Col Bras Exper Anim. 1998. v.3.

14. Cardoso CVP. Eutanásia. In: Andrade A, Pinto SC, Oliveira RS. Animais de laboratório: criação e experimentação. Rio de Janeiro: Fiocruz; 2002

15. Luna SPL, Teixeira MW. Eutanásia: considerações éticas e indicações técnicas. Rev CFMV. 2007; 13(41):60-9.

16. Qiu X. Biosynthesis of docosahexaenoic acid (DHA, 22:6-4,7,10,13,16,19): two distinct pathways. Prostaglandins Leukot Essent Fatty Acids. 2003; 68(2):181-6.

17. Schaeffer H, Gohlke M, Müller IM, Heid LJ, Palmer I, Kompauer $\mathrm{H}$, et al. Common genetic variants of the FADS1 FADS2 gene cluster and their reconstructed haplotypes are associated with the fatty acid composition in phospholipids. Hum Mol Genet. 2006; 15(11):1745-56.

18. Teitelbaum JE, Walker WA. Review: The role of omega 3 fatty acids in intestinal inflamation J Nutr Biochem. 2001; 12(1):21-32.

19. Jakobsson A, Westerberg R, Jacobsson A. fatty acid elongases in mammals: Their regulation and roles in metabolism. Prog Lipid Res. 2006; 45(3):237-49. 
20. Tahin QS. Importância fisiológica e patológica dos ácidos graxos. Arq Biol Tecnol. 1985; 28(3):335-61.

21. Ewin J. O Lado sadio das gorduras. $3^{\mathrm{a}}$ ed. Rio de Janeiro: Campus; 1997.

22. Carl JL, Richard VM, Mandeep RM,Hector OV.Omega-3 polyunsaturated fatty acids and cardiovascular diseases. JACC. 2009; 54(7):585-94.

23. Mattar M, Obeid O. Fish oil and the management of hypertriglyceridemia. Nutr Health. 2009; 20(1): 41-9

24. Mickleborough TD. Anti-inflammatory effects of polyunsaturated fatty acids on the inflammatory response in asthma. Agro Food Ind Hi-Tech. 2009; 20(4):10-2.

25. Ayala J, Lopez C, Hong A, Oberto C, Pavia A, Lares M. Effects of polyunsaturated fatty acids (Omega -3) on the platelet aggregation. Rev Latinoamer Hipertens. 2009; 4(3):71-8.

26. Kim HY. Novel metabolism of docosahexaenoic acid in neural cells. J Biol Chem. 2007; 282(26):18661-5

27. Chapkin RS, Kim W, Lupton JR, McMurray DN. Dietary docosahexaenoic and eicosapentaenoic acid: emerging mediators of inflammation. Prostag Leuk Essent Fatty Acids. 2009; 81(2-3):187-91.

28. Calviello G, Serini S, Piccioni E. n-3 polyunsaturated fatty acids and the prevention of colorectal cancer: Molecular mechanisms involved. Curr Med Chem. 2007; 14(29):81-9.

29. Andrade PMM, Carmo MGT. Ácidos graxos n-3: um link entre eicosanóides, inflamação e imunidade. Rev Mn-Metabólica. 2006; 8(3):135-43.

30. Cheatham CL, Colombo J, Carlson SE. n-3 fatty acids and cognitive and visual acuity development: methodologic and conceptual considerations. Am J Clin Nutr. 2006; 83(6):1458S-66S.

31. Wurtman RJ. Synapse formation and cognitive brain development: effect of docosahexaenoic acid and other dietary constituents. Metab Clin Exp. 2008; 57(10):S6-S10.

32. Adibhatla RM, Hatcher JF. Altered lipid metabolism in brain injury and disorders. Subcell Biochem. 2008; 49(1):241-68.

33. Calder P. n-3 Polyunsaturated fatty acids, inflammation, and inflammatory diseases. Am J Clin Nutr. 2006; 83 (suppl):1505S-19S.

34. Garófolo A, Petrilli AS. Balanço entre ácidos graxos ômega-3 e 6 na resposta inflamatória em pacientes com câncer e caquexia. Rev Nutr. 2006; 19(5): 611-21. doi: 10.1590/S1415-5273200600050000 9.

35. Luu NT, Madden J, Calder PC, Grimble R, Shearman $C P$, Chan $Y$, et al. Dietary supplementation with fish oil modifies the ability of human monocytes to induce an inflammatory response. J Nutr. 2007; 137(12):2769-74.

36. Innis SM. Fatty acids and early human development. Early Hum Dev. 2007; 83(12):761-66.

37. Zheng X, Tocher DR, Dickson CA, Bell JG, Teale AJ. Highly unsaturated fatty acid synthesis in vertebrates: new insights with the cloning and characterization of a delta 6 desaturase of Atlantic salmon. Lipids. 2005; 40(1):13-24

38. Wang Y, Botolin D, B. Christian B, Busik J, Xu J, Jump DB. Tissue-specific, nutritional, and developmental regulation of rat fatty acid elongases. J Lipid Res. 2005; 46(4):706-15

39. Barcelò-Coblijin G, Collison LW, Jolly CA, Murphy EJ. Dietary $\alpha$-linolenic acid increases brain but not heart and liver docosahexaenoic acid levels. Lipids. 2005; 40(8):787-98.

40. Harnack K, Andersen G, Somoza V. Quantitation of alpha-linolenic acid elongation to eicosapentaenoic and docosahexaenoic acid as affected by the ratio of n6/n3 fatty acids. Nutr Metab. 2009; 6(8):1-11.

41. MacDonald-Wicks LK, Garg ML. Incorporation of n-3 fatty acid into plasma and liver lipids of rats: Importance of background dietary fat. Lipids. 2004; 39(6):545-51.

42. Morise A, Combe N, Boué $C$, legrand $P$, Catherine $D$, Delplanque $B$, et al. Dose effect of $\alpha$-linolenic acid on PUFA conversion, bioavailability and storage in the hamster. Lipids. 2004; 39(4):325-34.

43. Barcelò-Coblijin G, Kitajka K, Puskas LG, Hogyes E, Zvara A, Hackler L, et al. Gene expression and molecular composition of phospholipids in rat brain in relation to dietary $n-6$ and n-3 fatty acid ratio. Biochim Biophys Acta. 2003; 1632(1-2):72-9.

44. Bowen RAR, Clandinin MT. High dietary 18:3n-3 increases in the $18: 3 n-3$ but not the $22: 6 n-3$ content in the whole body, brain, skin, epididymal fat pads and muscles of suckling rat pups. Lipids. 2000; 35(4):389-94.

45. Pawlosky RJ, Hibbeln JR, Lin, Y, Goodson S, Riggs $P$, Sebring $N$, et al. Effects of beef- and fi sh-based diets on the kinetics of n-3 fatty acid metabolism in human subjects. Am J Clin Nutr. 2003; 77(3): 565-72.

46. Vancassel S, Blondeau C, Lallemand S, Cador M, Linard A, Lavialle $M$, et al. Hyperactivity in the rat is associated with spontaneous low level of n-3 polyunsaturated fatty acids in the frontal córtex. Behav Brain Res. 2007; 180(2):119-26.

47. Uauy R, Valenzuela A. Marine oils: the health benefits of n-3 fatty acids. Nutrition. 2000; 16(7-8): 680-4. 
48. Surette ME. The science behind dietary omega-3 fatty acids. Can Med Assoc J. 2008; 178:177-80.

49. Institute of Medicine. Dietary Reference Intakes (DRIs) for energy, carbohydrate, fiber, fat, fatty acids, cholesterol, protein, and amino acids. Part 1. Washington (DC): National Academy Press; 2002.

50. Fürst $P$. The striking diet of the island of Crete: lipid nutrition from the palaeolithic to the affluent modern society. Clin Nutr. 2002; 21(S2):9-14.

51. Sinclair AJ, Attar-Bashi NM, Li D. What is the role of $\alpha$-linolenic acid for mammals? Lipids. 2002; 37(12):1113-23.

52. Jungestrom MB, Thompson LU, Dabrosin C. Flaxseed and its lignans inhibit estradiol-induced growth, angiogenesis, and secretion of vascular endothelial growth factor in human breast cancer xenografts in vivo. Clin Cancer Res. 2007; 13(3): 1061-7.

53. Chen J, Wang L, Thompson LU. Flaxseed and its components reduce metastasis after surgical excision of solid human breast tumor in nude mice. Cancer Lett. 2006; 234:168-75.

54. Sierra S, Lara-Villoslada M, Olivares M, Jiménez J, Boza J, Xaus J. La expresión de IL-10 interviene em la regulación de la respuesta inflamatória por los ácidos grasos omega 3. Nutr Hosp. 2004; 19(6): 376-82.

55. Calder P. Immunomodulation by omega-3 fatty acids. Prostaglandins, Leukot Essent Fatty Acids. 2007; 77(5-6):327-35.

56. Bernard G, Romano CC, Cacere CR, Juvenali M, Mendes-Giannini MJS, Duarte AJS. Imbalance of IL-2, IFN-gamma and IL-10 secretion in the imunosuppression associated with human paracoccidioidomycosis. Cytokine. 2001; 13(4): 248-52.

57. Hwang, D. Essential fatty acids and the immune response. FASEB J. 1989; 3:2052-61.

58. Bagga D, Wang L, Eisner-Farias R, Glaspy JA, Reddy ST. Differential effects of prostaglandin derived from $w-6$ and $w-3$ polyunsaturated fatty acids on COX-2 expression and IL-6 secretion. Proc Natl Acad Sci. 2003; 100(4):175-6.

59. Singer $P$, Shapiro $H$, Theilla M, Anbar R, Singer J, Cohen J. Anti-inflammatory properties of omega3 fatty acids in critical illness: novel mechanisms and an integrative perspective. Intensive Care Med. 2008; 34(9):1580-92.

60. Pompéia C, Lopes LR, Miyasaka CK, Procópio J, Sannomiya P, Curi R. Effect of fatty acids on leukocyte function. Braz J Med Biol Res. 2000; 33(11):1255-68.

61. Sijben JWC, Calder PC. Differential immunomodulation with long-chain n-3 PUFA in health and chronic disease. Proceed Nutr Soc. 2007; 66: 237-59.

62. Kelley DS. Modulation of human Immune and Inflamatory responses by dietary fatty acids. Nutrition. 2001; 17(7-8):669-73.

63. Marques AC, Valente TB, Rosa CS. Formação de toxinas durante o processamento de alimentos e as possíveis conseqüências para o organismo humano. Rev Nutr. 2009, 22(2):283-93. doi: 10.15 90/S1415-52732009000200010.

Recebido em: 16/2/2009

Versão final reapresentada em: 4/12/2009 Aprovado em: 12/5/2010 